\title{
The effects of catalyst pretreatment, growth atmosphere and temperature on carbon nanotube synthesis using $\mathrm{Co}-\mathrm{Mo} / \mathrm{MgO}$ catalyst
}

\author{
Atike Ince Yardimci ${ }^{\mathrm{a}}$, Selahattin Yllmaz ${ }^{\mathrm{b}}$, Yusuf Selamet ${ }^{\mathrm{c}, *}$ \\ a Department of Material Science and Engineering, Izmir Institute of Technology, Urla Izmir 35430, Turkey \\ b Department of Chemical Engineering, Izmir Institute of Technology, Urla Izmir 35430, Turkey \\ c Department of Physics, Izmir Institute of Technology, Urla Izmir 35430, Turkey
}

\section{A R T I C L E I N F O}

Article history:

Received 29 June 2015

Received in revised form 20 October 2015

Accepted 24 October 2015

Available online 28 October 2015

\section{Keywords:}

Carbon nanotube (CNT)

Chemical vapor deposition (CVD)

$\mathrm{Co}-\mathrm{Mo} / \mathrm{MgO}$ catalyst

Catalyst pretreatment atmosphere

CNT growth atmosphere

CNT growth yield

\begin{abstract}
A B S T R A C T
The growth of high quality and high yield carbon nanotubes (CNTs) by catalytic chemical vapor deposition (CVD) of $\mathrm{CH}_{4}$ over $\mathrm{Co}-\mathrm{Mo} / \mathrm{MgO}$ catalyst was investigated for different growth temperatures and $\mathrm{H}_{2}$ flow rates. It was observed that CNT yield decreased with the $\mathrm{H}_{2}$ flow rate, however, quality increased with increasing $\mathrm{H}_{2}$ flow rate. CNT yield increased for the temperatures $850-950{ }^{\circ} \mathrm{C}$ but dropped significantly above $950{ }^{\circ} \mathrm{C}$. In this study, the highest yield of $1526 \%$ was obtained at the growth temperature of $950{ }^{\circ} \mathrm{C}$. The optimum $\mathrm{H}_{2}$ flow rate was $200 \mathrm{sccm}$; this rate gave both high graphitization and high yield of product. Various CNT growth atmospheres including $\mathrm{Ar}, \mathrm{H}_{2}$ and the mixture of both gases were also analyzed and it was observed that the highest quality CNTs were obtained for both pretreatment and growth carried out with $\mathrm{H}_{2}$. This gave a high yield of $292 \%$. On the other hand, CNT growth carried out under Ar atmosphere gave higher CNT yield of 368\%, however, the CNTs grown with Ar were more defective and had larger diameters.

Prime novelty statement: We demonstrate a sorbitol added catalysis synthesis method and importance of the ideal growth conditions to improve high quality single walled carbon nanotube yield up to $1500 \%$.
\end{abstract}

(c) 2015 Elsevier B.V. All rights reserved.

\section{Introduction}

Catalytic chemical vapor deposition (CVD) is the dominant method to produce CNTs because of its high efficiency $[1,2]$. The main challenge is to obtain high yield of product with high crystalline structure. The scaled-up and reliable production of CNTs offers a wide range of possibilities to synthesize CNT for various applications such as memory devices [3], MEMs/NEMs [4], hydrogen storage [5], electrochemical actuators [6], and sensor applications [7-11].

The key parameters in CNT growth by CVD are the catalyst material [12], growth temperature [13,14], growth time [15], composition and the flow rate of the carrier and hydrocarbon gases [16].

The gas environment in CVD growth of CNT is an important parameter for final quality and yield [17-19]. In general, CNTs grown by the CVD method are found to be covered by amorphous carbon, therefore a diluting gas is needed to etch away amorphous carbon formation and prevent the catalyst from being poisoned. These gases are also used to control the decomposition rate while providing a suitable environment for the growth process. The gas composition also affects the CNT size, structure, morphology, and areal nanotube density [20-25]. Commonly used ambient gases are $\mathrm{N}_{2}$ [24], $\mathrm{H}_{2}$ [26] and $\mathrm{Ar}$ [27-29].

\footnotetext{
* Corresponding author.

E-mail address: yusufselamet@iyte.edu.tr (Y. Selamet).
}

$\mathrm{H}_{2}$ treatment affects the CNT synthesis [30]. A low areal density of CNTs was obtained when there was no $\mathrm{H}_{2}$ pretreatment, whereas, the catalyst particles agglomerated with very long $\mathrm{H}_{2}$ pretreatment leading to very low quality CNT growth. $\mathrm{H}_{2}$ is also essential for CNT growth [31], and it provides the activity of catalyst particles and optimization of CNT growth by adjusting reaction rate. The role of $\mathrm{H}_{2}$ in determining the final CNT quality through its effect on the catalyst crystal structure and morphology was also confirmed [32]. By increasing $\mathrm{H}_{2}$ amount CNT mean diameter can be dramatically decreased at high growth temperatures [33]. The growth mechanism of CNTs was studied in terms of the moderate etching of carbon deposited by hydrogen species and it was confirmed that hydrogen species etched the amorphous carbon deposited on the catalyst nanoparticles [34-35].

Appropriate growth temperature also is a key parameter in high quality CNT growth [13,36-40]. The growth rate, diameter, areal density, and crystallinity of CNT can be optimized with the growth temperature. The effects of growth temperature on the microstructure of CNTs grown at $600-750{ }^{\circ} \mathrm{C}$ by using the $\mathrm{Fe}(\mathrm{CO})_{5}-\mathrm{C}_{2} \mathrm{H}_{2}-\mathrm{H}_{2}$ system was studied [41]. It was found that the CNT length increased with the growth temperature up to $700^{\circ} \mathrm{C}$, and then quickly decreased at $750^{\circ} \mathrm{C}$. At higher temperatures, the formation of defect-free graphitic layers increases while at lower temperatures the graphitization degree decreases and amorphous carbon formation occurs [42]

In this study, the effect of $\mathrm{H}_{2}$ flow rate and temperature on CNT yield and quality was examined on Co-Mo/MgO catalyst using $\mathrm{CH}_{4}$ as 
a carbon precursor. Various catalyst pretreatment and CNT growth atmospheres were studied and best environment for both pretreatment and growth processes was searched.

\section{Materials and methods}

In the present study, CNTs were synthesized over $\mathrm{Co}-\mathrm{Mo} / \mathrm{MgO}$ nanocatalyst particles which were prepared by the gel-combustion method [43]. The molar ratio of $\mathrm{Co}: \mathrm{Mo}: \mathrm{MgO}$ was 0.5:0.25:10 which corresponds to 1.06 wt.\% Co and 0.86 wt.\% Mo in the initial gel. For the preparation of the catalyst, $\mathrm{Co}\left(\mathrm{NO}_{3}\right)_{2} \cdot 6 \mathrm{H}_{2} \mathrm{O},\left(\mathrm{NH}_{4}\right)_{5} \mathrm{Mo}_{7} \mathrm{O}_{24} \cdot 4 \mathrm{H}_{2} \mathrm{O}$ and $\mathrm{Mg}\left(\mathrm{NO}_{3}\right)_{2} \cdot 6 \mathrm{H}_{2} \mathrm{O}$ salts and $\mathrm{C}_{6} \mathrm{H}_{14} \mathrm{O}_{6}$ (sorbitol) were dissolved in deionized water. Then, the solution was dried at $100{ }^{\circ} \mathrm{C}$ for $3 \mathrm{~h}$ to produce a uniform gel. This step was followed by a flash calcination of the gel in an oven at $550{ }^{\circ} \mathrm{C}$ for $30 \mathrm{~min}$. Then, the material was grounded into a powder in a mortar. The powder was sieved with meshes of sizes between $75-250 \mu \mathrm{m}$. The catalyst particles were characterized by $\mathrm{X}$-ray diffraction (XRD) and scanning electron microscopy (SEM).

CNTs were synthesized by the thermal CVD method at atmospheric pressure in a quartz tube of $1 \mathrm{in}$. diameter. A catalyst amount weighing 15.0 mg was used in each run for CNT growth. Carbon source was $\mathrm{CH}_{4}$ and it was diluted with $\mathrm{H}_{2}$ and/or Ar at different flow rates. The temperature during the catalyst pretreatment step was ramped to $850^{\circ} \mathrm{C}$ with a rate of $5{ }^{\circ} \mathrm{C} / \mathrm{min}$ and kept at this temperature for $1 \mathrm{~h}$. Then, the temperature was set to the CNT growth temperature with the same rate. Carbon source was $\mathrm{CH}_{4}$ and $\mathrm{Ar}, \mathrm{H}_{2}$ or $\mathrm{Ar}-\mathrm{H}_{2}$ mixture was sent to the system to dilute $\mathrm{CH}_{4}$ during the CNT growth. For all sets of experiments CNT growth time was kept for $40 \mathrm{~min}$ and to terminate the growth, $\mathrm{CH}_{4}$ flow was stopped and the system was left to cool under the same flow of gases sent for the pretreatment process. Obtained product was weighed for yield calculation. Yield of CNTs was calculated using the formula of $\left[\left(W_{\text {out }}-W_{\text {in }}\right) / W_{\text {in }}\right] \cdot 100 \%$, where $W_{\text {in }}$ was the weight of the catalyst before reaction and $W_{\text {out }}$ was the weight of the CNT product after subtracting the weight of amorphous carbon calculated using TGA data.

Catalyst was pretreated under $\mathrm{H}_{2}$ atmosphere and after this reduction process, temperature was increased to CNT growth temperature for growth temperatures higher than $850{ }^{\circ} \mathrm{C}$. The studied growth temperatures were $850,900,950,1000{ }^{\circ} \mathrm{C}$. At the growth stage, $50 \mathrm{sccm}$ $\mathrm{CH}_{4}$ and $\mathrm{H}_{2}$ with different flow rates were sent into the system for 40 min. The investigated $\mathrm{H}_{2}$ flow rates were $50,100,150$ and $200 \mathrm{sccm}$.

After CNT growth temperature and $\mathrm{H}_{2}$ ratio, CNT growth atmosphere was investigated. At catalyst pretreatment process $\mathrm{Ar}, \mathrm{H}_{2}$ and $\mathrm{Ar}-\mathrm{H}_{2}$ mixture were examined using total gas flow of $200 \mathrm{sccm}$. Then, temperature was raised to the CNT growth temperature of $1000{ }^{\circ} \mathrm{C}$. The CNT growth was investigated under $\mathrm{Ar}, \mathrm{H}_{2}$ and $\mathrm{Ar}-\mathrm{H}_{2}$ mixture, possibly different from the pretreatment, keeping the total gas flow at $250 \mathrm{sccm}$ for $40 \mathrm{~min}$, and including a $\mathrm{CH}_{4}$ flow with different flow rates. $\mathrm{CNT}$ growth temperature was kept at $1000{ }^{\circ} \mathrm{C}$.
CNT growths were analyzed with SEM, thermo-gravimetric analysis (TGA), Raman spectroscopy, and transmission electron microscopy (TEM).

\section{Results and discussion}

A SEM image of the Co-Mo/MgO catalyst is given (Fig. 1a). The catalyst consisted of flake-like particles with sizes ranging between $75-250 \mu \mathrm{m}$. The XRD scan of catalyst particles (Fig. 1b) gave peaks associated with the $\mathrm{MgO}$ support particles. There was no observable peak for Co or Mo. This could be due to their nanometer size and high dispersion of $\mathrm{Co}$ and Mo throughout MgO.

\subsection{The effects of growth temperature and hydrogen flow rate}

Fig. 2 displays SEM images of CNTs synthesized under different growth temperatures and $\mathrm{H}_{2}$ flow rates of $200 \mathrm{sccm}$. Under the growth conditions studied here, all samples had a high CNT population. SEM analysis pointed that growth temperature was a significant parameter on CNT structural quality. The effect of temperature on the morphology of CNTs was that at low temperatures as-grown CNTs were often found in a tangled form which was an indication of larger number of structural defects compared to that of straight CNTs. Therefore, the critical challenge was to improve the quality of CNTs. With increasing growth temperature, the amount of tangled CNTs decreased and at a temperature of $1000{ }^{\circ} \mathrm{C}$ CNTs were much more ordered and untangled for all $\mathrm{H}_{2}$ flow rates.

Increasing $\mathrm{H}_{2}$ flow rate also effected CNT morphology for all temperatures studied in this work. The quality of the tubes was improved when $\mathrm{H}_{2}$ flow was increased from $50 \mathrm{sccm}$ to $200 \mathrm{sccm}$ for all four growth temperatures. The highest crystal quality nanotubes were grown at a growth temperature of $1000{ }^{\circ} \mathrm{C}$ and under $\mathrm{H}_{2}$ flow rate of $200 \mathrm{sccm}$ (Table 1).

Fig. 3 shows the Raman spectra of CNTs at different growth temperatures at $\mathrm{H}_{2}$ flow of $200 \mathrm{sccm}$. The quality of the as-grown CNTs was studied by Raman spectroscopy. The low intensity of the D-band $\left(1340 \mathrm{~cm}^{-1}\right)$ relative to the $\mathrm{G}$-band $\left(1580 \mathrm{~cm}^{-1}\right)$ indicated a very low defect density and high crystallinity of the sample grown at $1000{ }^{\circ} \mathrm{C}$. At lower growth temperatures disorder level increased. For all four growth temperatures RBM peaks were observed at 150 and $200 \mathrm{sccm}$ $\mathrm{H}_{2}$ flow rate. Different RBM peaks appeared in the wavenumber range of $100-300 \mathrm{~cm}^{-1}$ with different excitation wavelengths as they came to resonance with different phonon modes of various chiralities [44]. Generally samples grown under low $\mathrm{H}_{2}$ flow rates did not have RBM peaks. This indicated that higher $\mathrm{H}_{2}$ flow rates were more appropriate for SWCNT growth.

The ratios of $\mathrm{I}_{\mathrm{G}} / \mathrm{I}_{\mathrm{D}}$ of the CNTs are given in Table 1 . At $850{ }^{\circ} \mathrm{C}$ the lowest $\mathrm{I}_{G} / \mathrm{I}_{\mathrm{D}}$ ratios were observed indicating the highly disordered tubes,
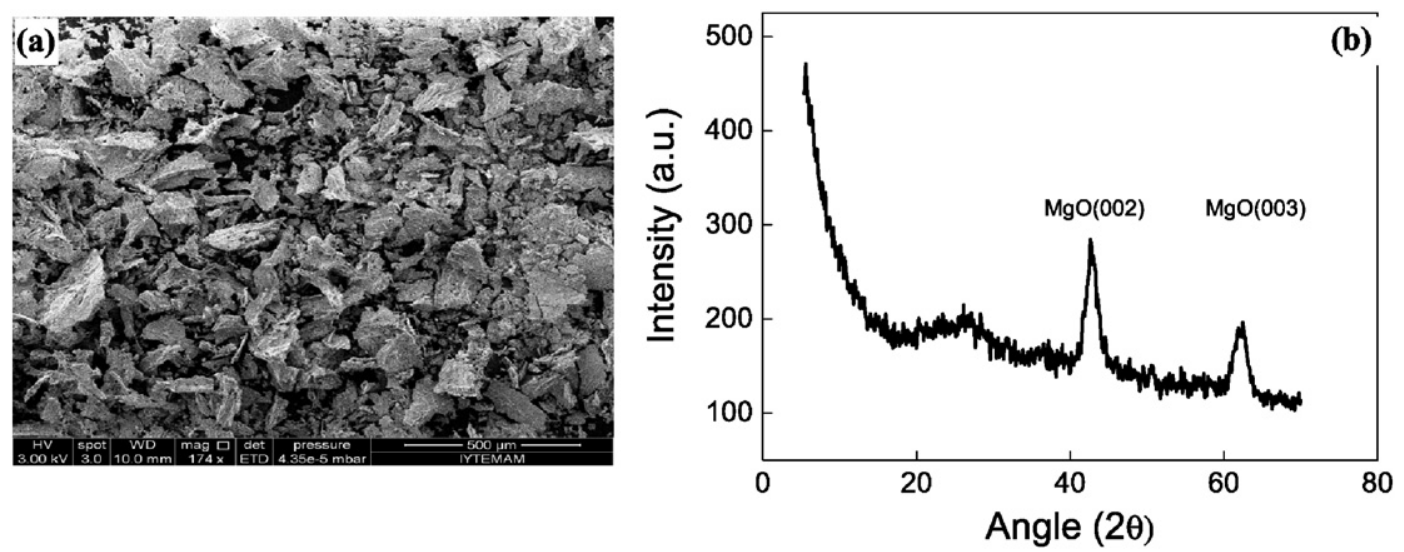

Fig. 1. (a) SEM image and (b) XRD scan of $\mathrm{Co}-\mathrm{Mo} / \mathrm{MgO}$ catalyst. 

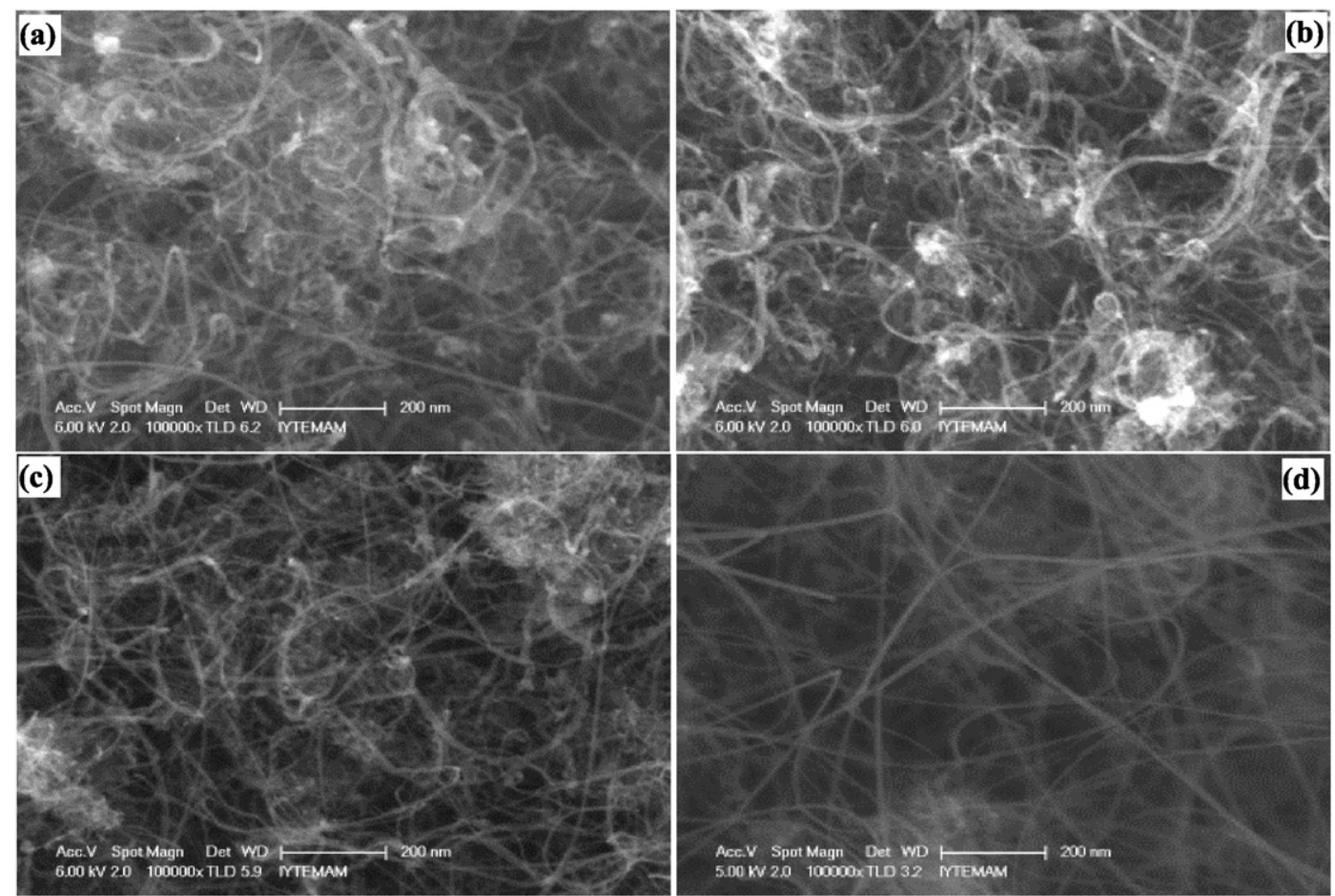

Fig. 2. SEM pictures of CNTs grown at (a) 850, (b) 900, (c) 950, and (d) $1000{ }^{\circ} \mathrm{C}$ under $200 \mathrm{sccm}$ hydrogen flow; all scale bars are $200 \mathrm{~nm}$.

high amorphous carbon content and hence, lower quality CNTs with respect to other growth temperatures. At $900{ }^{\circ} \mathrm{C} \mathrm{I}_{\mathrm{G}} / \mathrm{I}_{\mathrm{D}}$ ratios increased relative to $850{ }^{\circ} \mathrm{C}$ and with increasing $\mathrm{H}_{2}$ flow rate less defective and hence, higher quality CNTs were observed. At $950{ }^{\circ} \mathrm{C}$, all $\mathrm{H}_{2}$ flow rates yielded $\mathrm{I}_{\mathrm{G}} / \mathrm{I}_{\mathrm{D}}$ ratios relatively higher compared to other growth temperatures. When the results of $1000{ }^{\circ} \mathrm{C}$ growth were analyzed, it was noted that for this temperature and for all $\mathrm{H}_{2}$ flow rates used at this temperature CNT quality was quite high. The highest $\mathrm{I}_{\mathrm{G}} / \mathrm{I}_{\mathrm{D}}$ ratio of 13.63 for this study was obtained at $1000{ }^{\circ} \mathrm{C}$ and $200 \mathrm{sccm} \mathrm{H} \mathrm{H}_{2}$ flow rate.

TGA analysis was carried out in order to obtain the deposited carbon content of the product. Amorphous carbon amounts are given in Table 1. Amorphous carbon content monotonically decreased with increasing growth temperature. CNTs grown under $850{ }^{\circ} \mathrm{C}$ gave larger amount of amorphous carbon compared to the other temperatures. The lowest amorphous contents were observed at growth temperature of $1000{ }^{\circ} \mathrm{C}$

Table 1

Raman $\mathrm{I}_{G} / \mathrm{I}_{\mathrm{D}}$, amorphous carbon ratios and yields of CNTs.

\begin{tabular}{|c|c|c|c|c|c|}
\hline \multirow{2}{*}{$\begin{array}{l}\text { Catalyst } \\
\text { pretreatment } \\
\text { conditions } \\
\mathrm{H}_{2}(\mathrm{sccm})\end{array}$} & \multicolumn{2}{|c|}{$\begin{array}{l}\text { CNT growth } \\
\text { conditions }\end{array}$} & \multirow[t]{2}{*}{$\begin{array}{l}\text { Amorphous } \\
\text { carbon \% }\end{array}$} & \multirow[t]{2}{*}{$\begin{array}{l}\text { Raman } \\
\mathrm{I}_{\mathrm{G}} / \mathrm{I}_{\mathrm{D}} \text { ratio }\end{array}$} & \multirow[t]{2}{*}{$\begin{array}{l}\text { Yield } \\
\%\end{array}$} \\
\hline & $\mathrm{H}_{2}(\mathrm{sccm})$ & $\begin{array}{l}\text { Temperature } \\
\left({ }^{\circ} \mathrm{C}\right)\end{array}$ & & & \\
\hline 50 & 50 & 850 & 16.4 & 1.85 & 825 \\
\hline 100 & 100 & & 16.2 & 1.57 & 816 \\
\hline 150 & 150 & & 27.5 & 3.53 & 678 \\
\hline 200 & 200 & & 7.8 & 2.63 & 795 \\
\hline 50 & 50 & 900 & 8.6 & 1.56 & 1501 \\
\hline 100 & 100 & & 7.6 & 3.18 & 1094 \\
\hline 150 & 150 & & 8.4 & 5.89 & 1024 \\
\hline 200 & 200 & & 5.8 & 6.11 & 1093 \\
\hline 50 & 50 & 950 & 8.2 & 5.64 & 722 \\
\hline 100 & 100 & & 6.7 & 4.64 & 635 \\
\hline 150 & 150 & & 8.2 & 5.70 & 489 \\
\hline 200 & 200 & & 2.3 & 7.01 & 1526 \\
\hline 50 & 50 & 1000 & 3.5 & 3.25 & 779 \\
\hline 100 & 100 & & 3.9 & 5.57 & 397 \\
\hline 150 & 150 & & - & 5.87 & 339 \\
\hline 200 & 200 & & 3.1 & 13.63 & 292 \\
\hline
\end{tabular}

When the amount of amorphous carbon formed under different $\mathrm{H}_{2}$ flow rates was compared, it was observed that at high $\mathrm{H}_{2}$ flow CNT amount increased. The highest quality CNT amount was synthesized under $200 \mathrm{sccm} \mathrm{H}_{2}$ flow for all CNT growth temperatures.

Raman spectra, TGA and SEM data were in good agreement assessing the quality of CNTs; the disorder level decreased with increasing temperature and increasing $\mathrm{H}_{2}$ flow rate.

The yields of growths also are given in Table 1. The highest CNT yield was obtained at $950{ }^{\circ} \mathrm{C}$ under $200 \mathrm{sccm} \mathrm{H}_{2}$ and the obtained yield was very high: $1526 \%$. It was observed that $950{ }^{\circ} \mathrm{C}$ was an optimum temperature to obtain the highest yield. On the other hand, the low yield obtained at $1000{ }^{\circ} \mathrm{C}$ might be due to the possible changes in the character of the catalyst material with the temperature. Highly reactive

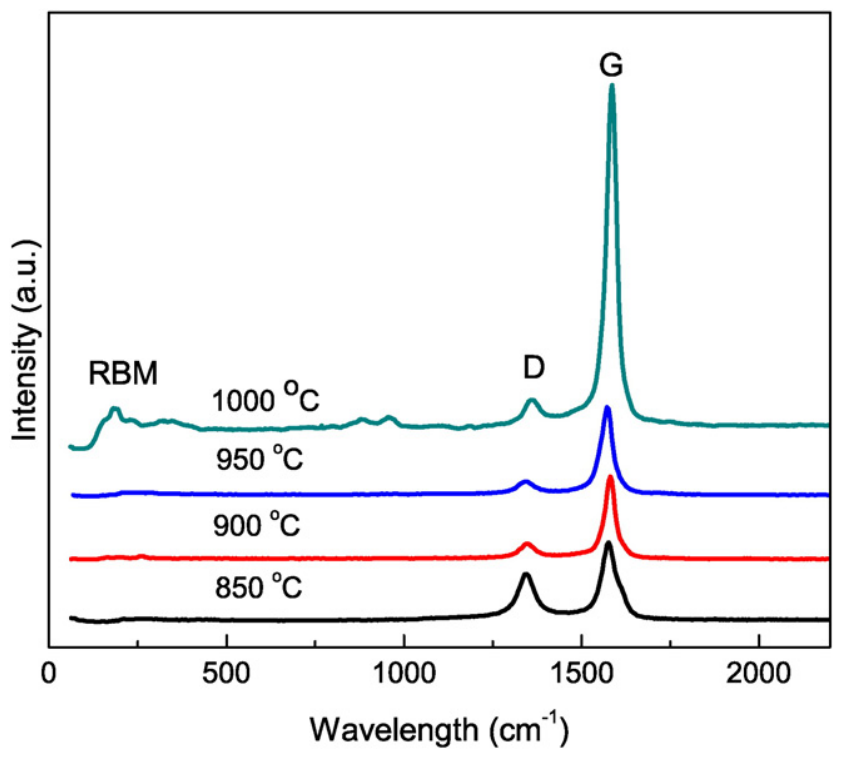

Fig. 3. Raman spectra of as-grown CNTs grown at (a) 850 , (b) 900 , (c) 950 , and (d) $1000^{\circ} \mathrm{C}$ at $\mathrm{H}_{2}$ flow of $200 \mathrm{sccm}$. 
Table 2

Amorphous carbon amounts and yields of CNTs grown under different pretreatment and growth atmospheres.

\begin{tabular}{|c|c|c|c|c|c|c|}
\hline \multicolumn{2}{|c|}{ Catalyst pretreatment atmosphere } & \multicolumn{3}{|c|}{ CNT growth atmosphere } & \multirow[t]{2}{*}{ Amorphous carbon \% } & \multirow[t]{2}{*}{ Yield \% } \\
\hline $\mathrm{H}_{2}(\mathrm{sccm})$ & $\operatorname{Ar}(\mathrm{sccm})$ & $\mathrm{CH}_{4}(\mathrm{sccm})$ & $\mathrm{H}_{2}(\mathrm{sccm})$ & $\operatorname{Ar}(\mathrm{sccm})$ & & \\
\hline 200 & - & 50 & 200 & - & 2.8 & 292 \\
\hline- & 200 & & & & 7.9 & 93 \\
\hline 10 & 190 & & & & 3.2 & 243 \\
\hline 200 (at pretreatment) $^{\mathrm{a}}$ & 200 (at heating) & & & & 6.7 & 67 \\
\hline 200 & - & 20 & 20 & 210 & 4.4 & 140 \\
\hline- & 200 & & & & 6.9 & 41 \\
\hline 10 & 190 & & & & 5.9 & 174 \\
\hline 200 (at pretreatment) $^{\mathrm{a}}$ & 200 (at heating) & & & & 6.3 & 68 \\
\hline 200 & - & 40 & - & 210 & 3.1 & 349 \\
\hline- & 200 & & & & 2.0 & 172 \\
\hline 10 & 190 & & & & 2.1 & 237 \\
\hline 200 (at pretreatment) $^{\mathrm{a}}$ & 200 (at heating) & & & & 1.9 & 368 \\
\hline
\end{tabular}

a Pretreated differently: Heated up to $850{ }^{\circ} \mathrm{C}$ under $\mathrm{Ar}$ and kept at $850{ }^{\circ} \mathrm{C}$ under $\mathrm{H}_{2}$ for $1 \mathrm{~h}$, then switched to Ar.

conditions at very high temperature (above $950{ }^{\circ} \mathrm{C}$ ) might deactivate the catalyst before all metal particles were completely reduced. Below $1000{ }^{\circ} \mathrm{C}$ the number of reduced catalyst particles increased with increasing temperature, which might increase yield with increasing temperature. In this study, very high yield of CNT was obtained and it is very important for CNT commercial applications.

\subsection{CNT growth under different pretreatment and growth atmospheres}

Three different CNT growth conditions were investigated in this study. In the growth stage $\mathrm{Ar}, \mathrm{H}_{2}$ and the mixture of both gases were added in turn to $\mathrm{CH}_{4}$. Four different catalyst pretreatment conditions were examined for all three growths (Table 2).

Fig. 4a displays a SEM image of the sample synthesized under $\mathrm{H}_{2}$ pretreatment and $\mathrm{H}_{2}$ growth. It shows that CNTs were straight and nontangled. The TEM observation of CNTs (Fig. 4b) indicated high structural quality (less defective tubes). The growths consisted of both SWCNTs and MWCNTs. There was no catalyst particles observed inside the CNTs.

Raman spectrum of the same sample is given in Fig. 5. The low intensity of the D-band relative to the G-band showed a very low defect density and high crystallinity of this sample. Raman spectra collected at several points on this sample resulted in RBM peaks which indicated that the CNT growth mainly consists of SWCNTs.

The TGA curve of the sample gave highest $\mathrm{I}_{\mathrm{G}} / \mathrm{I}_{\mathrm{D}}$ ratio in Raman spectroscopy taken under an $\mathrm{O}_{2}$ atmosphere is given in Fig. 6. The significant weight loss between 500 and $600{ }^{\circ} \mathrm{C}$ is due to the carbon nanotubes; both SWCNTs and MWCNTs are oxidized between $500{ }^{\circ} \mathrm{C}$ and $600{ }^{\circ} \mathrm{C}$ [45]. The oxidation temperature of amorphous carbon is between $200{ }^{\circ} \mathrm{C}$ and $450{ }^{\circ} \mathrm{C}$. A very small decrease in weight in TGA curves within this temperature range indicates extremely low level of amorphous carbon formation, $2.8 \%$.

Obtaining a large amount of product for a given amount of catalyst is very important for many applications. Yields and amorphous carbon amounts for each sample are given (Table 2). The yields were $292 \%$ for the $\mathrm{H}_{2}$ pretreatment, $243 \%$ for the $\mathrm{Ar}+\mathrm{H}_{2}$ mixture pretreatment and below $100 \%$ for both the Ar-only and the Ar followed by $\mathrm{H}_{2}$ pretreatment conditions. In terms of CNT yield and structural quality, for the $\mathrm{H}_{2}$ growth condition, pretreatment in pure $\mathrm{H}_{2}$ atmosphere had the highest yield and least amount of impurities. This could be due to reduction of metal oxide to metal catalyst during the pretreatment process as metal nanoparticles are more suitable for CNT growth.

In terms of both yield and quality, $\mathrm{Ar}+\mathrm{H}_{2}$ atmosphere growth condition yielded CNTs with characteristics generally inferior to those of CNTs grown under $\mathrm{H}_{2}$ atmosphere. The highest product yield of all growth conditions was observed in growths carried under Ar atmosphere. However, SEM images showed that the mean diameters were larger than the previous two growth conditions containing $\mathrm{H}_{2}$.

Amorphous carbon amount of the samples was calculated from TGA graphs and given in Table 2. The results indicated that catalyst particle reduction by $\mathrm{H}_{2}$ during pretreatment provided samples with lower amorphous carbon content. However, if $\mathrm{H}_{2}$ flow continued during growth stage after $\mathrm{H}_{2}$ pretreatment, $\mathrm{H}_{2}$ prevented amorphous carbon formation during growth process, but if Ar taken place at growth after $\mathrm{H}_{2}$ pretreatment, then amorphous carbon amount increased. Another analyzed combination is both pretreatment and growth taken place under Ar atmosphere. CNTs with larger diameters were obtained. However, amorphous carbon ratio was lower. Observation of low amorphous carbon content may also be attributed to the well-known annealing effect of an an inert atmosphere at high temperatures [29]; $\mathrm{Ar}$ increases the purity of the treated material by eliminating amorphous
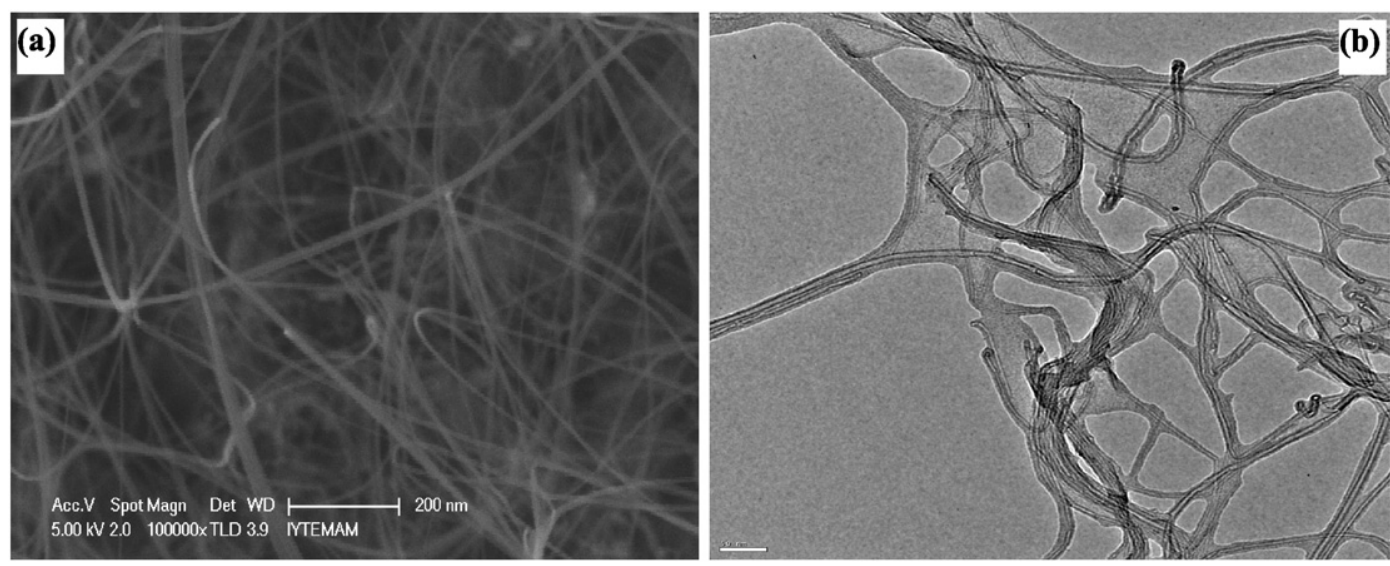

Fig. 4. (a) SEM image and (b) TEM image of the sample pretreated and grown under $\mathrm{H}_{2}$ atmosphere. 


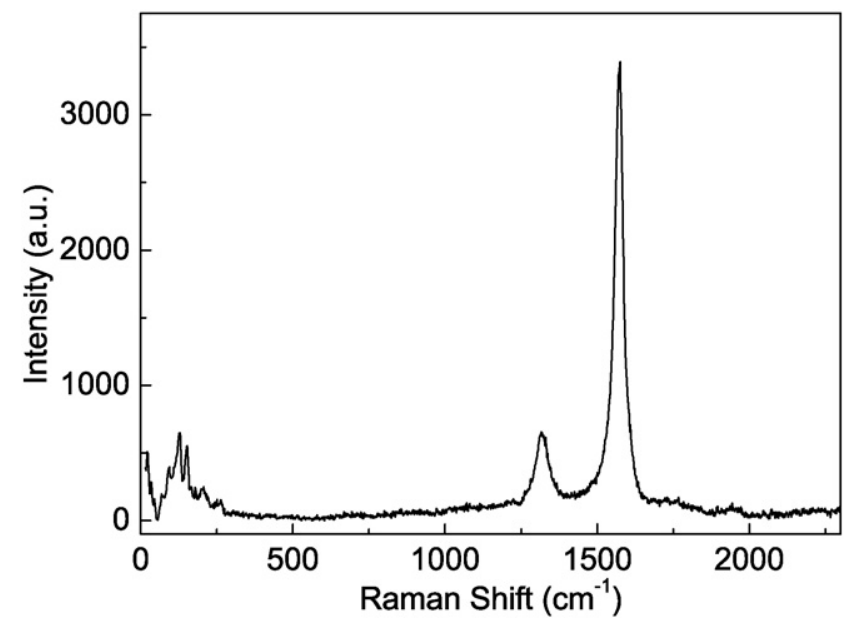

Fig. 5. Raman spectrum of the sample pretreated and grown under $\mathrm{H}_{2}$ atmosphere at flow of $200 \mathrm{sccm}$.

carbon and other non-desired materials, which therefore improves the purity of the synthesized CNTs.

Raman spectra $\mathrm{I}_{\mathrm{G}} / \mathrm{I}_{\mathrm{D}}$ ratios are plotted against pretreatment and growth parameters in Fig. 7 . $\mathrm{I}_{\mathrm{G}} / \mathrm{I}_{\mathrm{D}}$ ratios indicated that the growth carried out under $\mathrm{H}_{2}$ atmosphere gave very small disorder level for all four pretreatment conditions. On the other hand, growths carried under $\mathrm{Ar}+\mathrm{H}_{2}$ atmosphere showed higher disorder level for both $\mathrm{H}_{2}$ and $\mathrm{Ar}$ pretreatments. However, $\mathrm{Ar}+\mathrm{H}_{2}$ and $\mathrm{H}_{2}$ for $1 \mathrm{~h}$ pretreatments resulted with relatively higher graphitization. For growths under $\mathrm{Ar}$ atmosphere, the highest graphitization was obtained for $\mathrm{H}_{2}$ for $1 \mathrm{~h}$ pretreatment. The disorder level increased when Ar only pretreatment was applied. CNTs obtained under Ar growth atmosphere were more disordered, compared to those obtained under $\mathrm{H}_{2}$ and $\mathrm{Ar}+\mathrm{H}_{2}$ growth atmospheres with the same pretreatment conditions. As a result, the highest $\mathrm{I}_{\mathrm{G}} / \mathrm{I}_{\mathrm{D}}$ ratio was obtained for the sample grown with $\mathrm{H}_{2}$ pretreatment followed by $\mathrm{H}_{2}$ atmosphere growth.

Rashidi et al. synthesized $\mathrm{Co}-\mathrm{Mo} / \mathrm{MgO}$ catalyst using different organic additives and tested these catalysts for CNT growth. Among investigated organic additives, sorbitol gave the best results in terms of CNT quality and yield. Obtained CNT was single walled with yield of 180 wt.\% and Raman $I_{G} / I_{D}$ value of 9.3 [43]. The results presented in our study represent an extremely high yield SWCNT growth with $292 \mathrm{wt}$.\% yield value by using Co-Mo/MgO catalyst synthesized by the gel-combustion method using sorbitol as organic additive and $\mathrm{CH}_{4}$ as a carbon precursor at $1000^{\circ} \mathrm{C}$. However, in this study, by decreasing the CNT growth temperature to $850{ }^{\circ} \mathrm{C}$, yield was increased higher

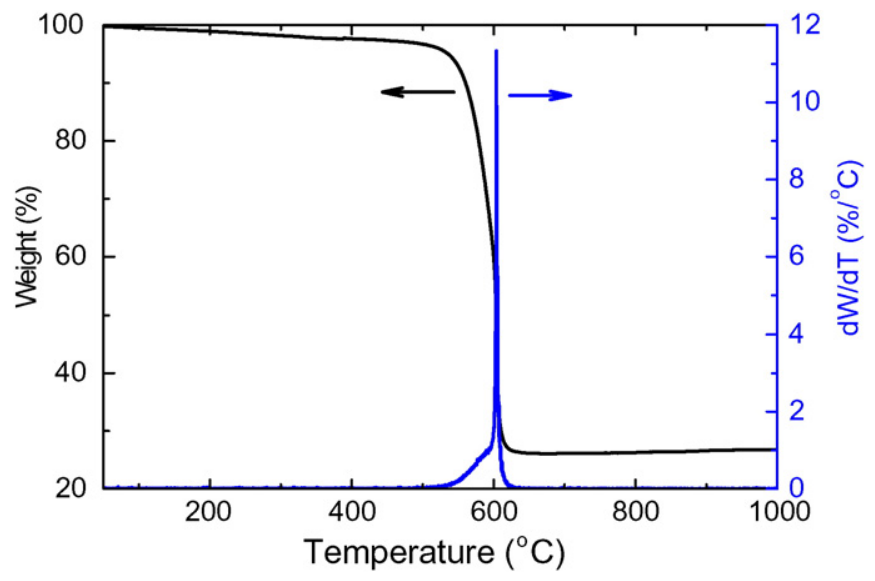

Fig. 6. TGA-DTA curve of the sample pretreated and grown under $\mathrm{H}_{2}$ atmosphere.

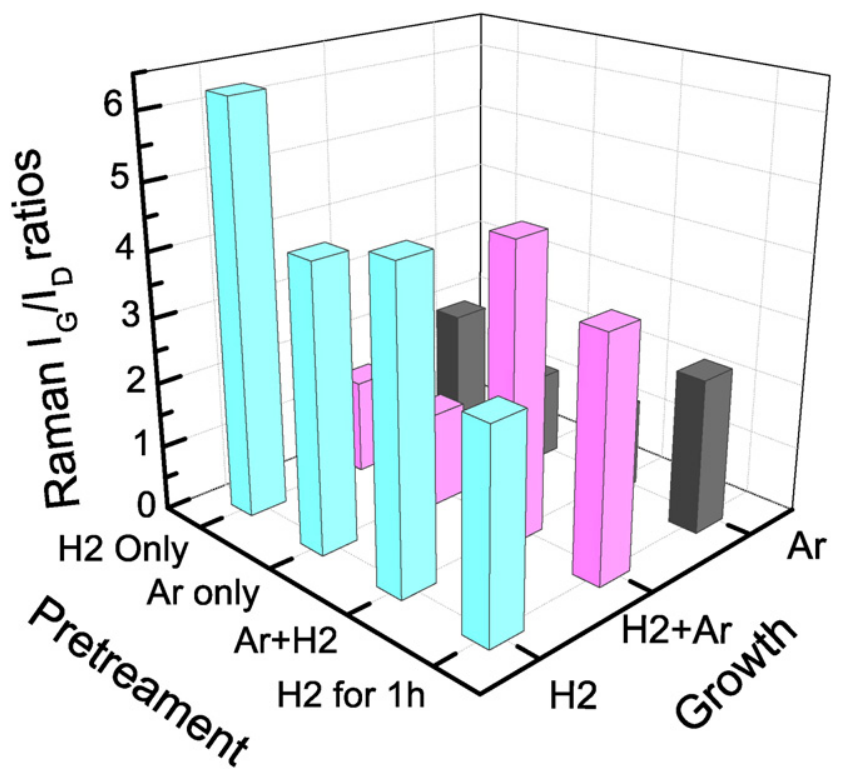

Fig. 7. Raman $I_{G} / I_{D}$ ratios of CNTs grown under $\mathrm{H}_{2}, \mathrm{Ar}+\mathrm{H}_{2}$ and $\mathrm{Ar}$ atmospheres at $1000{ }^{\circ} \mathrm{C}$ for $40 \mathrm{~min}$ for four different catalyst pretreatment conditions.

than $1500 \mathrm{wt} . \%$. There is a significant correspondence between high growth temperatures and high crystalline quality for $\mathrm{CH}_{4}$ catalytic decomposition, therefore, graphitization decreased at lower growth temperatures. In our study, the solution of this problem was found with $\mathrm{H}_{2}$ positive effect on CNT crystalline quality. As seen from Raman spectra even at low growth temperatures Raman $\mathrm{I}_{\mathrm{G}} / \mathrm{I}_{\mathrm{D}}$ ratios were high indicating a good graphitization degree at high $\mathrm{H}_{2}$ flow rates. In the absence of $\mathrm{H}_{2}$ yield and quality both decreased. Yeoh et al. obtained 304 wt.\% MWCNT yield with Co-Mo/MgO catalyst using citric acid as organic additive at $800^{\circ} \mathrm{C}[46]$ using $\mathrm{N}_{2}$ as an ambient gas for catalyst pretreatment and CNT growth processes. In literature large scale MWCNT synthesis was available with different catalysts. MWCNT with 4-7 wall number was achieved by catalytic decomposition of $\mathrm{CH}_{4}$ on Fe-Mo/MgO catalyst with 450 wt.\% yield [47]. Using Ni-Mo/MgO catalyst synthesized by the combustion method using polyethylene glycol 200 (PEG200) as combustion additive and $\mathrm{H}_{2}-\mathrm{CH}_{4}$ mixture for CNT growth MWCNTs with 9-20 nm diameter were synthesized. Obtained yield with this $\mathrm{Ni}-\mathrm{Mo} / \mathrm{MgO}$ catalyst was about $4500 \mathrm{wt}$ \% [48]. Milone et al. investigated the effect of Co phase on the on CNT growth [49]. Catalytic behavior of physically mixed $\mathrm{CoO} / \mathrm{MgO}+\mathrm{MgMoO}_{4}$ and $\mathrm{CoMoO}_{4}+\mathrm{MgMoO}_{4}$ was studied and citric acid was used as combustion additive. They found that the crystalline phase of Co was also important for large scale CNT production. $\mathrm{Co}$ in the form of $\mathrm{CoMoO}_{4}+\mathrm{MgMoO}_{4}$ gave the best result with 2407 wt.\% MWCNT yield. Overall, our study was in agreement with literature about the catalytic activity of $\mathrm{Co}-\mathrm{Mo} / \mathrm{MgO}$ catalyst for CNT growth. However, compared to other studies sorbitol as an organic additive for the combustion method provided SWCNT with high quality. Different catalyst pretreatment and CNT growth conditions were investigated in this study and large scale SWCNT growth was obtained and improved by using $\mathrm{H}_{2}$ and high temperature positive effects on CNT yield and quality.

\section{Conclusion}

CNT quality and yield were affected by growth temperature, atmosphere and pretreatment. High growth temperatures (950 and $1000^{\circ} \mathrm{C}$ ) provided high structural quality CNT growth, however, CNT yield was higher at lower temperatures. At $\mathrm{H}_{2}$ flow rates, higher quality, straighter, and largely amorphous carbon free CNTs were obtained. For the growth parameters used in this study, the maximum yield of $1526 \%$, 
and of high quality, with $\mathrm{I}_{\mathrm{G}} / \mathrm{I}_{\mathrm{D}}$ ratio of $7.01 \mathrm{CNTs}$ were obtained at $950{ }^{\circ} \mathrm{C}$ under $200 \mathrm{sccm} \mathrm{H}_{2}$ flow rate.

$\mathrm{H}_{2}$ was found to be necessary for both pretreatment and growth atmosphere for high quality CNT growth. $\mathrm{H}_{2}$ provided cleaner and higher crystalline CNT formation. It reduced carbonaceous product formation at growth stage. Using Ar CNT yield could be increased, but the growth resulted with larger diameter CNTs with more defects.

\section{Acknowledgments}

This study was supported by funding from projects 2008IYTE35 and 105T462. We thank IYTE Material Research Center for SEM images.

\section{References}

[1] J.-F. Colomer, C. Stephan, S. Lefrant, G.V. Tendeloo, I. Willems, Z. Konya, A. Fonseca, C. Laurent, J.B. Nagy, Large-scale synthesis of single-wall carbon nanotubes by catalytic chemical vapor deposition (CCVD) method, Chem. Phys. Lett. 317 (1) (2010) 83-89.

[2] V. Shanov, W. Cho, R. Malik, N. Alvarez, M. Haase, B. Ruff, N. Kienzle, T. Ochmann, D. Mast, M. Schulz, CVD growth, characterization and applications of carbon nanostructured materials, Surf. Coat. Technol. 230 (2013) 77-86.

[3] A. Star, Y. Lu, K. Bradley, G. Gruner, Nanotube optoelectronic memory devices, Nano Lett. 4 (9) (2004) 1587-1591.

[4] X. Zang, Q. Zhou, J. Chang, Y. Liu, L. Lin, Graphene and carbon nanotube (CNT) in MEMS/NEMS applications, Microelectron. Eng. 132 (2015) 192-206.

[5] Z. Ozturk, C. Baykasoglu, A.T. Celebi, M. Kirca, A. Mugan, A.C. To, Hydrogen storage in heat welded random CNT network structures, Int. J. Hydrog. Energy 40 (1) (2015) 403-411.

[6] Y. Yun, V. Shanov, Y. Tu, M.J. Schulz, S. Yarmolenko, S. Neralla, J. Sankar, S. Subramaniam, A multi-wall carbon nanotube tower electrochemical actuator. Nano Lett. 6 (4) (2006) 689-693.

[7] D.W. Kim, J.S. Lee, G. Lee, L.J. Overzet, M.E. Kozlov, A. Aliev, Carbon nanotubes based methanol sensor for fuel cells application, J. Nanosci. Nanotechnol. 6 (11) (2006) 3608-3613.

[8] Y.M. Wong, W.P. Kang, J.L. Davidson, A. Wisitsora-at, K.L. Soh, A novel microelectronic gas sensor utilizing carbon nanotubes for hydrogen gas detection, Sensors Actuators B Chem. 93 (1) (2003) 327-332.

[9] P. Mishra, S. Islam, Trace level ammonia sensing by SWCNTs (network/film) based resistive sensor using a simple approach in sensor development and design, Int. Nano Lett. 3 (1) (2013) 1-9.

[10] I.V. Anoshkin, A.G. Nasibulin, P.R. Mudimela, M. He, V. Ermolov, E.I. Kauppinen, Single-walled carbon nanotube networks for ethanol vapor sensing applications, Nano Res. 6 (2) (2013) 77-86.

[11] L.-C. Wang, K.-T. Tang, I.-J. Teng, C.-T. Kuo, C.-L. Ho, H.-W. Kuo, T.-H. Su, S.-R. Yang, G.-N. Shi, C.-P. Chang, A single-walled carbon nanotube network gas sensing device, Sensors 11 (8) (2011) 7763-7772.

[12] A.C. Dupuis, The catalyst in the CCVD of carbon nanotubes-a review, Prog. Mater. Sci. 50 (8) (2005) 929-961.

[13] C.J. Lee, J. Park, Y. Huh, J.Y. Lee, Temperature effect on the growth of carbon nanotubes using thermal chemical vapor deposition, Chem. Phys. Lett. 343 (1) (2001) 33-38.

[14] M.A. Pasha, R. Poursalehi, M.A. Vesaghi, A. Shafiekhani, The effect of temperature on the TCVD growth of CNTs from LPG over Pd nanoparticles prepared by laser ablation, Phys. B Condens. Matter 405 (16) (2010) 3468-3474.

[15] Q.W. Li, X.F. Zhang, R.F. DePaula, L.X. Zheng, Y.H. Zhao, L. Stan, T.G. Holesinger, P.N. Arendt, D.E. Peterson, Y.T. Zhu, Sustained growth of ultralong carbon nanotube arrays for fiber spinning, Adv. Mater. 18 (23) (2006) 3160-3163.

[16] A. Okita, Y. Suda, A. Oda, J. Nakamura, A. Ozeki, K. Bhattacharyya, Effects of hydrogen on carbon nanotube formation in $\mathrm{CH}_{4} \mathrm{H}_{2}$ plasmas, Carbon 45 (7) (2007) 1518-1526.

[17] D. Nishide, H. Kataura, S. Suzuki, K. Tsukagoshi, Y. Aoyagi, Y. Achiba, High-yield production of single-wall carbon nanotubes in nitrogen gas, Chem. Phys. Lett. 372 (1) (2003) 45-50.

[18] E. Borowiak-Palen, E. Borowiak-Palen, T. Pichler, X. Liu, M. Knupfer, A. Graff, O. Jost, W. Pompe, R.J. Kalenczuk, J. Fink, Reduced diameter distribution of single-wall carbon nanotubes by selective oxidation, Chem. Phys. Lett. 363 (5) (2002) 567-572.

[19] H. Yu, Q. Zhang, Q. Zhang, Q. Wang, G. Ning, G. Luo, F. Wei, Effect of the reaction atmosphere on the diameter of single-walled carbon nanotubes produced by chemical vapor deposition, Carbon 44 (9) (2006) 1706-1712.

[20] M. Bell, K. Teo, W. Milne, Factors determining properties of multi-walled carbon nanotubes/fibres deposited by PECVD, J. Phys. D. Appl. Phys. 40 (8) (2007) 2285.

[21] J.B.O. Caughman, L.R. Baylor, M.A. Guillorn, V.I. Merkulov, D.H. Lowndes, L.F. Allard, Growth of vertically aligned carbon nanofibers by low-pressure inductively coupled plasma-enhanced chemical vapor deposition, Appl. Phys. Lett. 83 (6) (2003) 1207-1209.
[22] T.Y. Lee, J.-H. Han, S.H. Choi, J.-B. Yoo, C.-Y. Park, T. Jung, Effects of source gases on the growth of carbon nanotubes, Diam. Relat. Mater. 12 (3) (2003) 851-855.

[23] P.E. Nolan, D.C. Lynch, A.H. Cutler, Carbon deposition and hydrocarbon formation on group VIII metal catalysts, J. Phys. Chem. B 102 (21) (1998) 4165-4175.

[24] D.J. Yang, Q. Zhang, S.F. Yoon, J. Ahn, S.G. Wang, Q. Zhou, Q. Wang, J.Q. Li, Effects of oxygen and nitrogen on carbon nanotube growth using a microwave plasma chemical vapor deposition technique, Surf. Coat. Technol. 167 (2) (2003) 288-291.

[25] K.B.K. Teo, Catalytic synthesis of carbon nanotubes and nanofibers, Encycl. Nanosci. Nanotechnol. 10 (1) (2003).

[26] T.D. Makris, L. Giorgi, R. Giorgi, N. Lisi, E. Salernitano, CNT growth on alumina supported nickel catalyst by thermal CVD, Diam. Relat. Mater. 14 (3) (2005) 815-819.

[27] H. Ago, N. Uehara, N. Yoshihara, M. Tsuji, M. Yumura, N. Tomonaga, T. Setoguchi, Gas analysis of the CVD process for high yield growth of carbon nanotubes over metalsupported catalysts, Carbon 44 (14) (2006) 2912-2918.

[28] Q. Liu, Y. Ouyang, L. Zhang, Y. Xu, Y. Fang, Effects of argon flow rate and reaction temperature on synthesizing single-walled carbon nanotubes from ethanol, Physica E 41 (7) (2009) 1204-1209.

[29] C. Vallés, M. Pérez-Mendoza, W.K. Maser, M.T. Martínez, L. Alvarez, J.L. Sauvajol, A.M. Benito, Effects of partial and total methane flows on the yield and structural characteristics of MWCNTs produced by CVD, Carbon 47 (4) (2009) 998-1004.

[30] H.-C. Wen, K. Yang, K.-L. Ou, W.-F. Wu, R-C. Luo, C.-P. Chou, Carbon nanotubes grown using cobalt silicide as catalyst and hydrogen pretreatment, Microelectron. Eng. 82 (3) (2005) 221-227.

[31] G.Y. Xiong, Y. Suda, D.Z. Wang, J.Y. Huang, Z.F. Ren, Effect of temperature, pressure, and gas ratio of methane to hydrogen on the synthesis of double-walled carbon nanotubes by chemical vapour deposition, Nanotechnology 16 (4) (2005) 532.

[32] M.J. Behr, E.A. Gaulding, K.A. Mkhoyan, E.S. Aydil, Effect of hydrogen on catalys nanoparticles in carbon nanotube growth, J. Appl. Phys. 108 (5) (2010) (053303053303-053308)

[33] M. Aksak, Y. Selamet, Carbon nanotube diameter tuning using hydrogen amount and temperature on $\mathrm{SiO}_{2} / \mathrm{Si}$ substrates, Appl. Phys. A 100 (1) (2010) 213-222.

[34] S.-i. Honda, M. Katayama, K.-Y. Lee, T. Ikuno, S. Ohkura, K. Oura, H. Furuta, T. Hirao, Low temperature synthesis of aligned carbon nanotubes by inductively coupled plasma chemical vapor deposition using pure methane, Jpn. J. Appl. Phys. 42 (2003) 441.

[35] Y.Y. Lin, H.W. Wei, K.C. Leou, H. Lin, C.H. Tung, M.T. Wei, C. Lin, C.H. Tsai, Experimental characterization of an inductively coupled acetylene/hydrogen plasma for carbon nanofiber synthesis, J. Vac. Sci. Technol. B: Microelectron. Nanometer Struct. 24 (1) (2006) 97-103.

[36] T.X. Li, K. Kuwana, K. Saito, H. Zhang, Z. Chen, Temperature and carbon source effects on methane-air flame synthesis of CNTs, Proc. Combust. Inst. 32 (2) (2009) 1855-1861.

[37] R. Xiang, G. Luo, Z. Yang, Q. Zhang, W. Qian, F. Wei, Temperature effect on the substrate selectivity of carbon nanotube growth in floating chemical vapor deposition, Nanotechnology 18 (41) (2007) (415703).

[38] S. Bandow, S. Asaka, Y. Saito, A.M. Rao, L. Grigorian, E. Richter, P.C. Eklund, Effect of the growth temperature on the diameter distribution and chirality of single-wall carbon nanotubes, Phys. Rev. Lett. 80 (17) (1998) 3779-3782.

[39] C. Fantini, A. Jorio, M. Souza, M.S. Strano, M.S. Dresselhaus, M.A. Pimenta, Optical transition energies for carbon nanotubes from resonant Raman spectroscopy: environment and temperature effects, Phys. Rev. Lett. 93 (14) (2004) 147406.

[40] W. Li, J. Wen, Z. Ren, Effect of temperature on growth and structure of carbon nanotubes by chemical vapor deposition, Appl. Phys. A 74 (3) (2002) 397-402.

[41] D.-H. Kuo, M.-Y. Su, The effects of hydrogen and temperature on the growth and microstructure of carbon nanotubes obtained by the $\mathrm{Fe}(\mathrm{CO})_{5}$ gas-phase-catalytic chemical vapor deposition, Surf. Coat. Technol. 201 (22) (2007) 9172-9178.

[42] Y. Lin, A. Dichiara, D. He, P. Haghi-Ashtiani, J. Bai, Uniform diameter multi-walled carbon nanotubes with a controlled wall number obtained by a simple chemical vapor deposition method, Chem. Phys. Lett. 554 (2012) 137-142.

[43] A.M. Rashidi, M.M. Akbarnejad, A.A. Khodadadi, Y. Mortazavi, A. Ahmadpourd, Single-wall carbon nanotubes synthesized using organic additives to Co-Mo catalysts supported on nanoporous MgO, Nanotechnology 18 (31) (2007) 315605.

[44] T.K. Yamabe, K. Fukui, K. Tanaka, The Science and Technology of Carbon Nanotubes, 1st ed. Elsevier, Japan, 1999.

[45] Z. Shi, Y. Lian, F. Liao, X. Zhou, Z. Gu, Y. Zhang, S. Iijima, Purification of single-wall carbon nanotubes, Solid State Commun. 112 (1) (1999) 35-37.

[46] W.-M. Yeoh, K.-Y. Lee, S.-P. Chai, K.-T. Lee, A.R. Mohamed, Synthesis of high purity multi-walled carbon nanotubes over $\mathrm{Co}-\mathrm{Mo} / \mathrm{MgO}$ catalyst by the catalytic chemical vapor deposition of methane, New Carbon Mater. 24 (2) (2009) 119-123.

[47] P. Dubey, S.K. Choi, J.H. Choi, D.H. Shin, C.J. Lee, Synthesis of thin-multiwalled carbon nanotubes by Fe-Mo/MgO catalyst using sol-gel method, Carbon Lett. 13 (2) (2012) 99-108.

[48] Y. Li, X.B. Zhang, X.Y. Tao, J.M. Xu, W.Z. Huang, J.H. Luo, Z.Q. Luo, T. Li, F. Liu, Y. Bao, H.J. Geise, Mass production of high-quality multi-walled carbon nanotube bundles on a Ni/Mo/MgO catalyst, Carbon 43 (2) (2005) 295-301.

[49] C. Milone, E. Piperopoulos, M. Lanza, S. Santangelo, A. Malara, E. Mastronardo, S Galvagno, Influence of the cobalt phase on the highly efficient growth of MWNTs, Nanomater. Nanotechnol. 4 (1) (2014) 1-8. 